REVES - Revista Relações Sociais, Vol. 04 N. 04 (2021)

https://periodicos.ufv.br/reves

elSSN: 2595-4490

REVES-ReVista Relacōes Sociais (eISSN 2595-4490)

\title{
Benefícios e desafios na prática do pregão eletrônico
}

Benefits and challenges in the practice of electronic bidding

Pedro Torres de Melo Pedrosa

ORCID: https://orcid.org/0000-0002-4140-3768

UEMG, Brasil

E-mail: ptmpedrosa@gmail.com

Ricardo Alves Balbino

ORCID: https://orcid.org/0000-0002-9357-3355

UEMG, Brasil

E-mail: ricardo.alvesbalbino@gmail.com

Ronaldo de Salles

ORCID: https://orcid.org/0000-0002-7568-6153

UEMG, Brasil

E-mail: ronaldodesalles@yahoo.com.br

Davson Mansur Irffi Silva

ORCID: https://orcid.org/0000-0002-5452-2264

UEMG, Brasil

E-mail: davson.silva@uemg.br

Article Info:

Article history: Received 2021-07-05

Accepted 2021-08-04

Available online 2021-08-04

doi: 10.18540/revesvl4iss4pp12777-01-15e

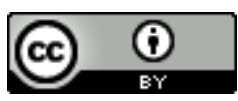

OPEN ACCESS

Resumo. Esse artigo aborda os desafios e benefícios no processo de aquisição de bens e serviços na modalidade pregão eletrônico. Trata-se de um estudo dos aspectos positivos e negativos do pregão eletrônico na aquisição de produtos e serviços, o qual busca relacionar e comparar os pontos de eficiência do processo licitatório. $O$ objeto de estudo é o processo de eficiência das aquisições de bens e serviços realizadas por instituições públicas no tocante à utilização do pregão eletrônico como modalidade licitatória. O objetivo deste estudo é relatar os aspectos positivos e negativos do pregão eletrônico na aquisição de bens e serviços em órgãos públicos. O tema tem relevância posto que é uma área do conhecimento que apresenta evoluções ao longo dos anos e as organizações públicas vivenciam essas alterações por ser palco dessas transformações. A situação problema que se apresenta é: o pregão eletrônico demonstra-se eficiente no tocante às aquisições de bens e serviços? A metodologia utilizada para o referido estudo é uma abordagem qualitativa, cuja pesquisa será bibliográfica e descritiva. Como resultados obtivemos 
informações que afirmam um aumento da eficiência com o uso da modalidade pregão eletrônico, apesar das dificuldades enfrentadas pelos órgãos públicos para a sua utilização.

Palavras-Chave: Processo Licitatório; Pregão Eletrônico; Governo.

Abstract. This article addresses the challenges and benefits in the process of acquiring goods and services in the electronic auction mode. It is a study of the positive and negative aspects of electronic trading in the acquisition of products and services, which seeks to relate and compare the efficiency points of the bidding process. The object of study is the process of efficiency in the acquisition of goods and services carried out by public institutions with regard to the use of electronic trading as a bidding modality. The objective of this study is to report the positive and negative aspects of the electronic auction in the acquisition of goods and services in public agencies. The theme has been that it is an area of knowledge that has evolved over the years and how associations experience these changes because it is the stage of these transformations. A problematic situation that arises is: is the electronic trading system proving to be efficient with regard to the acquisition of goods and services? The methodology used for the referred study is a qualitative approach, whose research will be bibliographic and descriptive. As a result, we obtained information that affirms an increase in efficiency with the use of the electronic auction modality, despite the difficulties faced by public agencies for its use.

Keywords: Bidding Process; Electronic Bidding; Government.

\section{Introdução}

As instituições públicas têm por princípio a aquisição de bens e serviços com base em um arcabouço jurídico dinâmico e robusto, composto pela Lei n.․ 8.666/93, cujo nome é considerado Lei Geral de Licitações, assim como na legislação correlata, a saber, a Lei Federal n.o 10.520/2002 de 2019 e Decreto n. .010 .024 de 2019. Dentre as suas modalidades de compras encontram-se: a Concorrência, a Tomada de Preços, a Carta Convite, o Concurso, a Dispensa de Licitação, Inexigibilidade, o Pregão Presencial e o Pregão Eletrônico. Cada um desses processos possui características específicas, sendo que a principal diferenciação está no valor aferido a cada modalidade.

O objeto de estudo deste artigo é o processo das aquisições de bens e serviços realizadas por órgãos públicos no tocante à utilização do pregão eletrônico como modalidade licitatória. A situação problema que se apresenta é: o pregão eletrônico demonstra-se eficiente no tocante às aquisições de bens e serviços em órgãos públicos?

O referido estudo justifica-se por se tratar de uma área do conhecimento que apresentou evoluções ao longo dos anos, principalmente, no que se refere à tratativa da coisa pública. As diversas evoluções que ocorreram nos últimos anos levaram às organizações públicas a vivenciarem essas alterações em razão das modificações ocorridas no cenário político-econômico e tecnológico, posto que esses agentes se colocaram como protagonistas no palco destas transformações.

O objetivo deste estudo é relatar os aspectos positivos e negativos do pregão eletrônico na aquisição de produtos e serviços em órgãos públicos. Para tanto, pretende-se como objetivos específicos: apresentar o conceito e as características da licitação na modalidade de pregão eletrônico; levantar os aspectos positivos e 
negativos do pregão eletrônico na aquisição de produtos e serviços; e, equacionar a relação custo versus benefícios com a prática do pregão eletrônico em processos licitatórios.

A metodologia utilizada para o referido estudo é uma abordagem qualitativa, com a realização de uma pesquisa bibliográfica com 0 tratamento de dados secundários e descritiva, pois foi pretendido realizar a prática da descrição dos dados e informações, no qual o tema é o pregão eletrônico. Essa pesquisa se caracteriza como sendo de natureza teórica e empírica.

Esse estudo inicia-se com essa breve introdução; na sequência apresenta-se - Referencial Teórico que se consubstancia em livros, artigos publicados nas principais revistas acadêmicas, leis, decretos, dentre outros meios que forem relevantes ao estudo. Em seguida, apresenta-se a metodologia utilizada, a análise dos resultados da pesquisa e, por fim, as considerações finais e as referências utilizadas.

\section{Fundamentação}

A Administração Pública, atualmente, executa diversas atividades que apontam no sentido de fazer valer o interesse público. Contudo, para chegar a cumprir suas metas e objetivos, a administração pública contrata serviços e produtos fornecidos por terceiros para atender as demandas próprias, assim como da sociedade. Fernandes (2015, p. 15) informa que:

As compras públicas representam uma parcela significativa do gasto público em um estado moderno. Atualmente, o crescente aumento de funções e responsabilidades que o estado acumula faz com que a demanda por produtos e serviços a serem entregues ou prestados ao ente público seja cada vez maior (FERNANDES, 2015, p. 15).

A necessidade de se estabelecer uma relação financeira com terceiros visa a realização de contratações de compra de bens e serviços por preços que sejam compatíveis à necessidade do Estado em adquirir produtos e serviços por preços que sejam vantajosos ao erário. Bem pensou o legislador ao criar leis que conduzissem todo o processo de contratação e escolha destes terceiros, uma vez que, a liberdade sem restrições, provocaria prejuízos aos interesses públicos. Spricigo e Fonseca (2008, p. 5) ressalvam: "A lei teve, como um dos seus propósitos, formalizar os procedimentos para compras e contratações, de modo a convergir com o viés mais "democrático" incorporado à Constituição de 1988 [...]" (SPRICIGO E FONSECA, 2008, p. 5).

Neste ínterim, a licitação visa conter os riscos da operação contratual, pois a licitação é um processo que ocorre antes da contratação, mas dela nasce a contrapartida financeira do Estado, logo, o procedimento de licitação conceder-lhe-á a escolha da melhor proposta ofertada de modo que as vantagens estejam em função dos interesses da coletividade (NOHARA, 2017).

\subsection{A Licitação}

No propósito de levantar as características e a definição do processo licitatório, Nohara (2017, p. 307) afirma que a: "licitação é o procedimento administrativo pelo qual um ente seleciona a proposta mais vantajosa entre as oferecidas para a celebração de contrato de seu interesse" (NOHARA, 2017, p. 307). Trata-se de um processo administrativo que legitima e fundamenta a celebração de um contrato administrativo, por meio da busca de propostas comerciais a fim de 
possibilitar à Administração Pública optar por aquela que seja mais vantajosa aos interesses públicos. Neste sentido, Carvalho Filho (2018, p. 310), conceitua o termo licitação da seguinte forma:

Podemos conceituar a licitação como o procedimento administrativo vinculado por meio do qual os entes da Administração Pública e aqueles por ela controlados selecionam a melhor proposta entre as oferecidas pelos vários interessados, com dois objetivos - a celebração de contrato, ou a obtenção do melhor trabalho técnico, artístico ou científico (Carvalho Filho, 2018, p. 310).

Um segundo fundamento é o da igualdade de oportunidades, que visa conceder oportunidades iguais aos que desejam fornecer produtos e serviços à Administração Pública. Ainda nesta seara, não é possível deixar de mencionar os princípios básicos norteadores do processo de licitação: o princípio da legalidade; impessoalidade; igualdade; publicidade; redigidos no Art. 37 da CF 1988, e probidade administrativa e vinculação ao instrumento convocatório (CARVALHO FILHO, 2018).

\subsubsection{O pregão eletrônico}

A lei estabelece que a modalidade pregão seja destinada a aquisição de bens e serviços comuns, os quais estão conceituados no parágrafo único do artigo $1^{\circ}$ da Lei $n^{\circ} 10.520$ de 2002: "[...] para aquisição de bens e serviços comuns, poderá ser adotada a licitação na modalidade de pregão, que será regida por esta Lei" (LEI № 10.520 DE 2002, ARTIGO 1ํ). O parágrafo único do art. 1ำ da Lei do Pregão define que são bens e serviços comuns, como sendo: "[...] aqueles cujos padrões de desempenho e qualidade possam ser objetivamente definidos pelo edital, por meio de especificações usuais no mercado" (LEI № 10.520 DE 2002, ARTIGO 1ํ, PARÁGRAFO ÚNICO).

Assim, as restrições e parâmetros instituídos no processo licitatório restringe a possibilidade de se realizar a contratação de obras públicas e de bens e serviços não qualificados como comuns, conforme aborda Carvalho Filho (2018, p.379):

[...] na verdade, são produtos cuja escolha se processa apenas com base nos preços ofertados, e isso porque são comparáveis entre si e dispensam avaliação detalhada. Como exemplos de bens comuns podem ser citados os materiais de expediente, máquinas comuns e veículos. Serviços comuns são, entre outros, os de vigilância, conservação e limpeza, gráficos, transporte, hotelaria e atividades de apoio, como os serviços de garçom, motorista, ascensorista, copeiro, mensageiro, secretária, telefonista e um sem número de outros do mesmo gênero (CARVALHO FILHO (2018, p.379).

A definição legal sobre o que são bens e serviços comuns está longe de ser precisa, haja vista que as expressões nela contidas são plurissignificativas (CARVALHO FILHO, 2018). A lei estabelece que tais bens e serviços são aqueles "[...] cujos padrões de desempenho e qualidade possam ser objetivamente definidos pelo edital, por meio de especificações usuais no mercado" (LEI n. $\left.{ }^{\circ} 10.520 / 02\right) 1$.

No Brasil, adota-se o pregão em sua modalidade eletrônica em contraposição à cultura do uso de papel, o processo burocrático instituído supera os trâmites internos de documentos físicos em instituições públicas, pois o uso da tecnologia

\footnotetext{
${ }^{1} \S$ Parágrafo único do Art. $1^{\circ}$ Lei 10.520/02.
} 
como aliada promove maior dinamicidade e agilidade ao processo de aquisição. Silva (2012, p. 10) considera que a utilização das Tecnologias da Informação promove maior transparência e rastreabilidade às informações, assim como 0 processo dessa conduta "[...] aumenta a segurança dos atos por inibir adulterações e por facilitar a responsabilização, bem como reforça o compromisso do servidor público [...]", conduzindo ao comportamento ético, fato promovedor de uma evolução à administração burocrática de despachos documentais.

Recentemente, o arcabouço jurídico que rege as licitações públicas foi alterado com a sanção da nova lei de licitações, a Lei no 14.133/2021. Em vigor a partir de 01 de abril de 2021. Esta nova legislação substitui - com prazo de até dois anos para transição - a Lei Geral das Licitações (Lei no 8.666/1993), a Lei do Pregão (Lei no 10.520/2002) e o Regime Diferenciado de Contratações/RDC (Lei no 12.462/11), além de agregar diversos temas relacionados a contratações públicas; porém, para este artigo não se aborda as alterações instituídas pela nova Lei de Licitações, pois além de ser muito recente, ainda não há embasamento teórico para analisar a sua eficiência.

A nova lei de licitações é considerada um marco na legislação nacional, tanto por unificar o arcabouço jurídico em uma única lei, como por inovar ao criar uma nova modalidade de licitação, a considerar, a extinção das modalidades: Tomada de Preços e a Carta Convite. Outra novidade instituída relaciona-se à escolha da modalidade de licitação, posto que não possui vínculo com o valor do objeto a ser contrato.

A modalidade do pregão é, quando comparada às modalidades ditas tradicionais (instituídas pela Lei Geral Licitações), relativamente recente, são adotados em dois tipos de pregão: o "pregão presencial" e o "pregão eletrônico". No primeiro, é exigida a presença física dos participantes, a relacionar os integrantes: os agentes da Administração (pregoeiro e equipe de apoio) assim como os interessados no fornecimento; já no segundo tipo, o processo acontece em ambiente virtual, por intermediado da tecnologia da informação com o uso da Internet. Um ponto relevante a considerar é: mais fornecedores conseguem participar do processo ofertando produtos e serviços, uma vez que a distância não se coloca como um impeditivo. Neste tipo de pregão, não há a necessidade da presença física dos interessados em participar da licitação, esta é a diferença fundamental entre o pregão presencial e eletrônico (CARVALHO FILHO, 2018).

Ao relacionar alguns pontos característicos dessa modalidade de licitação, Nohara (2017) lista algumas particularidades do pregão:

- Ausência de limitação quanto ao valor licitado;

- Recair sobre bens e serviços comuns;

- Inversão de fases;

- Possibilidade de negociação do valor pelo pregoeiro;

- Tipo de licitação: menor preço;

- Ausência de garantia de proposta; e

- Oportunidade única para impugnação do edital com um recurso administrativo.

Observa-se que o processo de mudança nos procedimentos licitatórios cria maiores e melhores possibilidades ao legislador, pois visa atender aos princípios fundamentais da licitação e, consequentemente, busca atender as demandas do ente público, seja na qualidade dos produtos e serviços com a conduta do menor preço. Diante desta realidade, as modificações na legislação ou nos procedimentos acabam trazendo dois efeitos, no primeiro, o legislador busca a eficiência em máximo grau possível e, no segundo, é dada a possibilidade de participação, 
princípio que torna iguais os direitos; a isonomia é um fator relevante no processo, pois não se configura direcionamento e nem, tão pouco, a oferta de privilégios à terceiros. Noutro ponto, observa-se que existem possibilidades quanto à eficiência dessa modalidade, ocasião que se coloca em não ser possível conhecer idoneidade dos participantes, como observa Heidrich e Mengden (2014, p. 31), quanto abordam a habilitação como "[...] é um procedimento que visa avaliar o licitante, no que diz respeito à sua idoneidade e capacidade de assumir obrigações contratuais, perante a Administração, na execução de determinado objeto". A ação é um ponto positivo, visto restringe o acesso daqueles que pretende dar prejuízo ao erário.

\subsubsection{Os aspectos positivos e negativos do pregão eletrônico}

O pregão eletrônico instituiu lisura na gestão pública. Agilidade e transparência são pontos determinantes desse processo, classificam o termo: economias ao erário e maior eficiência na contenção de gastos, essas são propostas que se destinam aos interesses da sociedade.

Na concepção de Carvalho Filho (2018, p. 370), as vantagens do Pregão Eletrônico são:

Primeiramente, reduz-se o uso de papel, já que os atos se produzem pela Internet. Depois, há menor sobrecarga para o pregoeiro, já que há menos documentos para analisar. Ainda: o pregão eletrônico é mais célere e eficaz quando se trata de licitação por itens ou lotes. Por fim, os recursos da tecnologia da informação aproximam as pessoas e encurtam as distâncias, permitindo atuação com maior eficiência por parte da Administração (CARVALHO FILHO, 2018, p. 370)

Freitas e Maldonado (2013, p 108) corroboram destacando outras vantagens proporcionadas por este instrumento licitatório na:

[...] celeridade dos procedimentos, a ampliação do leque de interessados e a maior transparência e publicidade dos atos administrativos. A maior celeridade é reflexo da redução de prazos e de exigências documentais. A ampliação do universo de interessados é consequência da possibilidade de participação do certame a distância, ou seja, empresas de qualquer localidade do país podem participar da sessão pública, por meio do acesso ao sistema pela internet. $O$ aumento da transparência e da publicidade dos atos deve-se à possibilidade de qualquer cidadão acompanhar em tempo real, também através da internet, o desenvolvimento das sessões públicas e os atos praticados por todos os envolvidos no procedimento licitatório (FREITAS E MALDONADO, 2013, p 108).

Segundo Cavalcante et al. (2017) esta foi a forma que a Administração Pública encontrou para dar transparência aos atos públicos, uma vez que o certame ocorre online e todos as informações referente ao processo tornam-se públicas e são armazenadas no sistema, fato que evita o erro material quanto ao julgamento do funcionário no processo licitatório.

No que tange aos importantes princípios da economicidade e da eficiência, Albiero e Silva (2018) consideram que são inegáveis a eficiência e a economia nas compras públicas, essas características estão associadas e, em conjunto, com a obrigatoriedade da aplicação de desses princípios, o pregão em sua forma eletrônica 
surgiria no sentido de oferecer maior transparência ao certame e gerenciar melhores qualidade à gestão dos recursos públicos.

Com todos os seus benefícios elencados, o pregão requer aperfeiçoamentos que sejam adequados à realidade, pois os avanços proporcionados na tecnologia exigem atualizações que oferecem maior eficiência ao uso da ferramenta. Percebese que muitos pregoeiros ainda estão despreparados e desatualizados, fatos que dificultam e tumultuam a realização do processo, como aponta Batista (2019).

As observações propostas no Batista (2019) elucidam algumas fragilidades que consideram que o sistema de pregão eletrônico não é de todo perfeito. $O$ sistema apresenta desvantagens que requerem a devida atenção das autoridades. Os ajustes se tornam necessários, pois essa é uma modalidade que vem sendo utilizada em formatos mais efetivos em algumas entidades e menos efetivos em outras. Algumas desvantagens precisam ser superadas, como por exemplo: a limitação e fragilidade; no que se refere à conexão de internet em muitos municípios no Brasil. A distância e a localização das metrópoles não oferecem a possibilidade de acesso de mão de obra qualificada, no interior essa é uma realidade que se coloca como pontual, pois os profissionais como maior expertise atuam onde há uma maior demanda, dessa forma, os pequenos municípios se colocam como reféns das suas peculiares características: localização, renda per capita, número de indivíduos na cidade, volume de recursos destinados à entidade local e outros pontos que se colocam como limitadores.

Na concepção de Carvalho Filho (2018, p. 379), são:

Como desvantagens, cite-se 0 fato de que várias pessoas federativas não têm ainda o sistema que lhes permita utilizar a modalidade eletrônica. O mesmo se diga de empresas de menor porte, que também não têm acesso à rede de informações. Da mesma forma, o pregão presencial será mais adequado quando houver necessidade de exibição de produtos ou de análise mais detalhada de planilhas de composição de custos, tarefa usualmente de grande complexidade (CARVALHO FILHO, 2018, p. 379), .

No viés contributivo, Sabatke (2020) apresenta uma desvantagem importante que precisará ser superada: a duração do pregão eletrônico; se comparado ao pregão presencial, o tempo dedicado é maior, fato que pode gerar maior eficiência ao processo e assim atender as demandas que se colocam como emergenciais.

Nesse sentido, Sabatke (2020) aliado aos pensamentos de Olivetti (2014), consideram que a duração dos pregões eletrônicos é $40 \%$ maior aos pregões presenciais; observa-se que a forma presencial de pregões se coloca como uma condição essencial para se obter agilidade na modalidade licitatória, o que contraria a hipótese inicial de que a forma eletrônica seria mais ágil a presencial.

Nas considerações dos autores, Olivetti (2014), Carvalho Filho (2018) e Sabatke (2020), observa-se que a escolha da modalidade tem uma relação direta com a necessidade da entidade pública, assim como as ferramentas tecnológicas disponíveis. Rosset e Finger (2016, p. 108) comungam dos pensamentos de Faria et al. (2010), os autores entendem que:

[...] após a implantação do pregão eletrônico, através do Decreto № $5.450 / 2005$, foram abertas possibilidades inéditas de maior transparência, ampliação de oportunidades de participação e de competição e disseminação de mecanismos de controle gerenciais [...] porém, mesmo com esse grande avanço nas compras públicas, ainda é necessário evoluir muito em relação ao sistema de compras do governo (ROSSET E FINGER, 2016, p. 108). 
A escolha da modalidade presencial ou eletrônica cria uma relação de dependência com a disponibilidade dos recursos e o acesso de fornecedores ao processo no local. Em municípios mais afastados das metrópoles, verifica-se que o acesso pode apresentar limitadores se considerado o deslocamento, enquanto que o pregão eletrônico se limita à capacitação humana e, também, a disponibilização dos equipamentos com os incrementos necessários.

\subsection{O processo de aquisição via pregão eletrônico}

O pregão eletrônico é realizado por meio de uma plataforma ou sistema informatizado que possibilita, por meio da internet, a sessão de licitação. Não cabe a cada ente público a criação de plataformas e sites que possibilitem a realização do pregão eletrônico. As entidades públicas podem utilizar diversos sistemas para operacionalizar o pregão eletrônico, inclusive um sistema desenvolvido pelo governo federal, cujo nome é “Comprasnet”, vide Quadro 1.

\begin{tabular}{|c|c|c|}
\hline Sistema & Ente / Empresa & CNPJ \\
\hline COMPRASNET & MINISTÉRIO DA ECONOMIA & $\ldots$ \\
\hline PREGÃO ELETRÔNICO SIGA / COMPRASBR & A Z INFORMÁTICA LTDA & $24.598 .492 / 0001-27$ \\
\hline PORTAL DE COMPRAS PÚBLICAS & ECUSTOMIZE CONSULTORIA EM SOFTWARE LTDA & $09.397 .355 / 0001-30$ \\
\hline COMPRASNET.GO & GOVERNO DO ESTADO DE GOIÁS & $01.409 .580 / 0001-38$ \\
\hline LANCE ELETRÔNICO & BOLSA DE LICITAÇÕES E LEILÕES DO BRASIL & $10.508 .843 / 0002-38$ \\
\hline BNC COMPRAS & BOLSA NACIONAL DE COMPRAS & $25.099 .967 / 0001-01$ \\
\hline LICITANET & LICITANET - LICITAÇÕES ELETRÔNICAS EIRELI & $21.280 .462 / 0001-80$ \\
\hline PE-INTEGRADO & SEC. DE ADMINISTRAÇÃO - GOVERNO DE PERNAMBUCO & $10.572 .022 / 0001-80$ \\
\hline BBMNET Licitaçסes & BOLSA BRASILEIRA DE MERCADORIAS & $05.342 .088 / 0001-43$ \\
\hline COE-RS & SEC PLANEJ, ORÇ E GESTÃO ESTADO RIO GRANDE DO SUL & $87.958 .682 / 0001-28$ \\
\hline SCPI & FIORILLI SOFTWARE LTDA & $01.704 .233 / 0001-38$ \\
\hline PORTAL DE COMPRAS MG & SEC PLANEJAMENTO E GESTÃO DE MINAS GERAIS & $05.461 .142 / 0001-70$ \\
\hline LICITAR DIGITAL & LICITAR DIGITAL SERVIÇOS EM TI LTDA & $35.125 .567 / 0001-79$ \\
\hline COMPRA ABERTA & COMPANHIA DE INFORMÁTICA DE JUNDIAÍ & $67.237 .644 / 0001-79$ \\
\hline e-LIC & SECRETARIA DE ESTADO DA ADM DE SANTA CATARINA & $82.951 .351 / 0001-42$ \\
\hline BR CONECTADO & GM TECNOLOGIA E INFORMAÇÃO LTDA & $15.464 .263 / 0001-29$ \\
\hline BOLSANET & RECOVERY SISTEMAS EIRELI & $13.436 .510 / 0001-58$ \\
\hline
\end{tabular}

Fonte: Plataforma Brasil (2021) ${ }^{2}$

Diversos outros sites e plataformas são mantidos pela iniciativa pública ou privada, todos atuam no sentido de operacionalizar o sistema de aquisição de produtos e serviços via pregão eletrônico. Com o propósito de informar o site relata que as disposições presentes no $\S 3$, do Art. $1^{\circ}$, do Decreto $n^{\circ} 10.024$, de 20 de setembro de 2019, que a Secretaria de Gestão, por meio do Departamento de Transferências da União (DETRU), comunica que foi disponibilizado o manual que contempla as orientações para a integração dos sistemas externos de compras eletrônicas com a Plataforma +Brasil.

2 Plataforma Brasil. Disponível em: http://plataformamaisbrasil.gov.br/ 
No site, os interessados podem realizar a consulta para se informar sobre as exigências e disposições necessárias para participar do certame. O processo iniciase com o credenciamento junto ao provedor ou sistema eletrônico; em seguida, é oferecido o nome da autoridade competente do órgão que realizará a licitação, do pregoeiro e sua equipe de apoio; e dos licitantes. Esse é um mecanismo que oferece vantagens e desvantagens, sendo que cada um se coloca na esfera e nas perspectivas do usuário.

\section{Metodologia}

A abordagem metodológica deste estudo foi qualitativa, pois verificou a extensão dos conceitos e teorias de autores, lei federais e abordagens teóricas de entidades do governo que consideram o tema. Minayo (2001) repousa na retórica de há um universo de valores, significados e motivações que atuam no sentido de caracterizar o estudo, construído de forma empírica e subjetiva. Matias-Pereira (2012) proporciona a compreensão de que a pesquisa qualitativa examina um fenômeno para descrevê-lo integralmente, diferenciando-o de outro.

Cooper e Schindler (2011) empreendem que a pesquisa qualitativa é um conjunto de técnicas de interpretação, cuja descrição e decodificação adotam um determinado significado. Trata-se de estudo das variedades de materiais empíricos de estudos de caso, entrevista textos, experiência pessoal, introspecção, e produções culturais.

O estudo se caracteriza como sendo de natureza teórica e empírica, o qual se constitui como sendo uma pesquisa bibliográfica; conforme preconiza Gil (2008, p. 50) em relevância ao tema, a pesquisa bibliográfica é: "[...] desenvolvida a partir de material já elaborado, constituído principalmente de livros e artigos científicos". O tratamento de dados secundários realiza uma prática descritiva dos fatos e informações que são apresentadas por autores cuja publicação de suas obras ilustram o viés do tema.

Brasileiro (2013, p. 45) pondera que a pesquisa descritiva:

[...] trata-se de uma pesquisa cujo fim é expor e caracterizar um fenômeno ou uma determinada população. Durante o estudo, o investigador utiliza instrumentos de coleta padronizada de dados, como questionário ou formulários de observação sistemática, no intuito de descrever os acontecimentos e estabelecer relações entre variáveis (Brasileiro, 2013, p. 45).

A pesquisa documental, outra característica desse estudo, é abraçada por Gil (2008, p. 51) como um recolhimento de "[...] materiais que não receberam ainda um tratamento analítico, ou que ainda podem ser reelaborados de acordo com os objetivos da pesquisa". Os materiais citados nesta pesquisa foram livros, artigos científicos de periódicos nacionais, decretos, leis e sites.

Quanto à finalidade, essa pesquisa pode ser considerada como exploratória, pois busca o desenvolvimento e o esclarecimento de conceitos. Gil (2008) elucida que a pesquisa exploratória é utilizada com o objetivo de fornecer uma visão geral sobre os fatos, de maneira a propiciar uma aproximação.

Diante das caracterizações apresentadas, será realizada no próximo capítulo a análise de conteúdo cujo procedimento é interpretativo, visto que se analisa, como embasamento, os documentos pesquisados (BRASILEIRO, 2021). Na próxima seção, os tópicos relacionados e considerados apresentam-se como sendo a pesquisa bibliográfica, propriamente dita. 


\section{Análise de Dados}

A análise dos dados foi baseada no levantamento bibliográfico realizado, tendo em vista o objetivo de relatar sobre a eficiência do processo de aquisição de bens e serviços por meio de pregão eletrônico em órgãos públicos.

Tendo como benefício principal e específico, o pregão eletrônico dispensa a presença física dos participantes (fornecedores). Contrário a essa modalidade, o pregão presencial requer o credenciamento junto ao pregoeiro, os fornecedores entregam os envelopes presencialmente ou via correios, para manifestarem suas propostas, e a documentação é entregue à parte. $O$ diferencial entre um tipo e outro está não somente na presença daqueles que querem participar, ocorre, também, no formato que ocorrerem a formalização das propostas e nos documentos exigidos para a devida participação, como expõe Carvalho Filho (2018).

O pregão eletrônico torna o processo torna-se mais ágil e mais versátil, pois é facilitado ao participante, na comodidade do seu trabalho realizar a prática da oferta de preços nos itens que serão adquiridos após o término do certame. No sistema eletrônico, os procedimentos são realizados com a postagem de documentos via web, em plataformas específicas que se propõe a esse fim, conforme determina o $\S$ 3, do Art. $1^{\circ}$, do Decreto $n^{\circ} 10.024 / 19$.

O Sebrae apresenta uma cartilha comparativa da sessão pública em cada situação, trata-se de um informativo direcionado àqueles que buscam informações sobre o tema, a Quadro 02 auxilia nos comparativos mais relevantes.

\section{Quadro 02 - Comparativos entre pregão presencial e eletrônico}

\begin{tabular}{|c|c|c|}
\hline & Pregão Presencial & Pregão Eletrônico \\
\hline $\begin{array}{l}\text { Sessão } \\
\text { Pública }\end{array}$ & $\begin{array}{l}\text { Sessão pública com a presença } \\
\text { de licitantes. }\end{array}$ & $\begin{array}{l}\text { Envio de informações à distância } \\
\text { (via internet) }\end{array}$ \\
\hline Abertura & $\begin{array}{l}\text { Credenciamento dos licitantes } \\
\text { interessados em participar. }\end{array}$ & $\begin{array}{l}\text { Os licitantes poderão participar da } \\
\text { sessão pública na internet } \\
\text { utilizando sua chave de acesso e } \\
\text { senha. }\end{array}$ \\
\hline $\begin{array}{l}\text { Classificaç } \\
\text { ão das } \\
\text { propostas }\end{array}$ & $\begin{array}{l}\text { O pregoeiro procederá abertura } \\
\text { dos envelopes contendo as } \\
\text { propostas de preço e classificará } \\
0 \text { autor da proposta de menor } \\
\text { preço. }\end{array}$ & $\begin{array}{l}\text { O pregoeiro verificará as } \\
\text { propostas, desclassificando } \\
\text { aquelas que não estejam em } \\
\text { conformidade com os requisitos } \\
\text { estabelecidos no edital. }\end{array}$ \\
\hline Lances & $\begin{array}{l}\text { O licitante autor da menor } \\
\text { proposta e os demais que } \\
\text { apresentarem preços até } 10 \% \\
\text { superiores a ela estão } \\
\text { classificados para a fase de } \\
\text { lances. Caso não haja pelo menos } \\
\text { três licitantes que atendam essas } \\
\text { condições, deverão ser } \\
\text { convocados para a fase os } \\
\text { demais, obedecida a ordem de } \\
\text { classificação das propostas, até o }\end{array}$ & $\begin{array}{l}\text { Todos os licitantes, cujas } \\
\text { propostas não foram } \\
\text { desclassificadas, podem oferecer } \\
\text { lances. }\end{array}$ \\
\hline
\end{tabular}


máximo de três, quaisquer que sejam os preços oferecidos.

Autoria dos Os presentes na sessão pública lances sabem quem são os autores das propostas.

É vedada a indicação dos licitantes responsáveis pelos lances.

Os licitantes são classificados, de forma sequencial e apresentam Ordem dos lances verbais, a partir do autor da lances proposta de maior preço e os demais em ordem decrescente de valor.

Término da

fase de Ocorre quando não houver lances lances menores que o último ofertado.
Habilitação A documentação deverá ser apresentada em envelope lacrado.

A intenção do licitante de recorrer

Recurso deve ser feita de forma verbal, no final da sessão com registro em ata da síntese das razões.

Adjudicaçã

0

A falta de manifestação autoriza o pregoeiro a adjudicar o item ao vencedor do certame.
Os licitantes podem oferecer lances sucessivos independente da ordem de classificação.

Ocorre por decisão do pregoeiro e o sistema eletrônico encaminha aviso de fechamento iminente dos lances, após o que transcorrerá período de até 30 minutos, aleatoriamente determinado.

Os documentos deverão ser enviados via fax após a solicitação do pregoeiro, ou de acordo com o encerramento da fase, conforme as cláusulas previstas no edital.

A intenção de recorrer pode ser realizada pelo licitante, de forma imediata e motivada, em campo próprio no sistema eletrônico.

A falta de manifestação autoriza o pregoeiro a adjudicar o item ao vencedor do certame.

Fonte: Sebrae (2017)

Pretendeu-se, com o Quadro 02, ter um ponto de controle sobre a aferição dos pontos positivos e negativos do Pregão Eletrônico, firmando uma comparação entre este e o Pregão Presencial, de maneira a subsidiar a análise comparativa entre estas modalidades de licitação.

O pregão eletrônico coloca-se como uma modalidade de licitação versátil, visto que abre possibilidades de interessados em participarem do processo à distância. Esse é um ponto positivo a considerar, posto que os ganhos pela livre concorrência de fazem presentes e minimizam os custos aferidos ao erário, como formalizam os estudos de Carvalho Filho (2018), cujas vantagens do Pregão Eletrônico são relatadas na redução do uso de papéis, uma menor sobrecarga de atividades junto ao pregoeiro, a realização ocorre pela internet em tempo real, o processo ganha velocidade quanto ao julgamento e outros pontos a relatar e serem considerados no processo licitatório. 


\subsection{A relação das modalidades de licitação}

O Quadro 03 mostra a legislação utilizada amparada pela Lei $n .{ }^{\circ} 8.666 / 93$ em: Dispensa de Licitação, Concorrência, Tomada de Preço, Carta convite, Concurso e Leilão; já o pregão ampara-se no Decreto n.․ 10.024/19.

\begin{tabular}{|c|c|c|c|}
\hline \multicolumn{4}{|c|}{ Quadro 03 - Modalidades e Limites Licitatórios } \\
\hline $\begin{array}{l}\text { Modalidad } \\
\quad \mathrm{e}\end{array}$ & Breve Conceito & $\begin{array}{l}\text { Limites: } \\
\text { obras e } \\
\text { serviços de } \\
\text { engenharia }\end{array}$ & $\begin{array}{l}\text { Limites: } \\
\text { compras e } \\
\text { demais } \\
\text { serviços }\end{array}$ \\
\hline $\begin{array}{l}\text { Dispensa } \\
\text { de licitação }\end{array}$ & $\begin{array}{l}\text { Pequeno valor; situações excepcionais; } \\
\text { razão do objeto; razão da pessoa. }\end{array}$ & $\begin{array}{l}\text { Até } \\
\mathrm{R} \$ 33.000,0 \\
0\end{array}$ & $\begin{array}{l}\text { Até } \\
\mathrm{R} \$ 17.600,0 \\
0\end{array}$ \\
\hline $\begin{array}{l}\text { Concorrên } \\
\text { cia }\end{array}$ & $\begin{array}{l}\text { A concorrência acontece entre quaisquer } \\
\text { interessados habilitados conforme o } \\
\text { edital. }\end{array}$ & $\begin{array}{l}\text { Acima de } \\
R \$ 3.300 .00 \\
0,00\end{array}$ & $\begin{array}{l}\text { Acima de } \\
R \$ 1.430 .00 \\
0,00\end{array}$ \\
\hline $\begin{array}{l}\text { Tomada } \\
\text { de preço }\end{array}$ & $\begin{array}{l}\text { Ocorre entre interessados devidamente } \\
\text { cadastrado até o } 3^{\circ} \text { dia anterior à data do } \\
\text { recebimento das propostas. }\end{array}$ & $\begin{array}{l}\text { Até } \\
\mathrm{R} \$ 3.300 .00 \\
0,00\end{array}$ & $\begin{array}{l}\text { Até } \\
\mathrm{R} \$ 1.430 .00 \\
0,00\end{array}$ \\
\hline Convite & $\begin{array}{l}\text { Há escolha por parte do Estado, sendo os } \\
\text { participantes cadastrados ou não, precisa } \\
\text { ter no mínimo três convidados, podendo } \\
\text { estender a mais interessados desde que } \\
\text { manifestem interesse com } 24 \text { horas de } \\
\text { antecedência. }\end{array}$ & $\begin{array}{l}\text { Até } \\
\mathrm{R} \$ 330.000 \\
00\end{array}$ & $\begin{array}{l}\text { Até } \\
\mathrm{R} \$ 176.000 \\
00\end{array}$ \\
\hline Concurso & $\begin{array}{l}\text { É a modalidade de licitação entre } \\
\text { quaisquer interessados para escolha de } \\
\text { trabalho técnico, científico ou artístico, } \\
\text { mediante a instituição de prêmios ou } \\
\text { remuneração aos vencedores, conforme } \\
\text { critérios constantes de edital publicado na } \\
\text { imprensa oficial com antecedência } \\
\text { mínima de } 45 \text { (quarenta e cinco) dias. }\end{array}$ & & \\
\hline Leilão & $\begin{array}{l}\text { É a modalidade de licitação entre } \\
\text { quaisquer interessados para a venda de } \\
\text { bens móveis inservíveis para a } \\
\text { administração ou de produtos legalmente } \\
\text { apreendidos ou penhorados, ou para a } \\
\text { alienação de bens imóveis previstos no } \\
\text { art. 19, a quem oferecer o maior lance, } \\
\text { igual ou superior ao valor da avaliação. }\end{array}$ & & \\
\hline Pregão & $\begin{array}{l}\text { É uma modalidade que visa por meio de } \\
\text { lances atingir um menor preço. }\end{array}$ & $\begin{array}{l}\text { Não há } \\
\text { limites }\end{array}$ & $\begin{array}{l}\text { Não há } \\
\text { limites }\end{array}$ \\
\hline
\end{tabular}

Fonte: Os autores (2021). 
Os valores expressos no quadro fazem jus aos pensamentos de Fernandes (2015), demonstrando o montante a ser aferido aos processos licitatórios que ocorrem em todo território nacional. Atuar no sentido de minimizar os custos desses processos é uma forma de otimizar o uso dos recursos públicos, pois o uso adequado e consciente é uma forma não somente de demonstrar eficácia, mas, principalmente, em atender uma parcela maior das necessidades da sociedade.

No Quadro 03, observa-se que o pregão não tem previsão de limites de valores financeiros, ao contrário das outras modalidades instituídas pela Lei ํㅡㄴ 8.666/1993. O Artigo 37 da Constituição Federal preconiza os princípios norteadores que não somente dão fé ao ato público, mas oferecem lisura ao processo licitatório.

\section{Considerações Finais}

O objeto de estudo do referido artigo foi o processo das aquisições de bens e serviços realizadas por órgãos públicos no tocante à utilização do pregão eletrônico como modalidade licitatória. A situação problema apresentada, refere-se à verificação da eficiência do pregão eletrônico no tocante às aquisições de bens e serviços. Diante das exposições apresentadas, observa-se que essa modalidade de licitação é vantajosa e os ganhos são significativos tanto para entidades públicas e quanto para privadas.

O relato dos pontos demonstrou a eficiência do pregão eletrônico no tocante às aquisições de bens e serviços; quando considerada a eficácia no processo e a redução de custos diretos e indiretos ao certame, verifica-se que as entidades públicas e privadas tendem a apresentarem ganhos em escala, visto que uma série de processos licitatórios, na ocorrência dos fatos, levam as entidades públicas e privadas a apresentarem maiores ganhos no longo prazo. Esse é um ponto que favorece a administração pública, pois a obtenção dos resultados financeiros ocorre na data presente e tendem a serem mais expressivos nas relações futuras.

Ao ponderar sobre os aspectos positivos e negativos do pregão eletrônico na aquisição de produtos e serviços em órgãos públicos, verifica-se que o objetivo foi alcançado, uma vez, em cada um dos objetivos específicos apresentados: apresentar o conceito de licitação e as características da modalidade de pregão eletrônico; levantar os aspectos positivos e negativos do pregão eletrônico na aquisição de produtos e serviços; e, equacionar a relação custo versus benefícios com a prática do pregão eletrônico em processos licitatórios; promoveu a construção empírica dos fatos que culminaram no objetivo geral deste estudo.

O pregão eletrônico está sujeito a apresentar desvantagens; a principal delas é que vários entes da federação não possuem ainda um sistema que lhes possibilite usufruir da modalidade eletrônica. O uso das plataformas de pregão eletrônico apresenta-se como um desafio a ser vencido por algumas entidades públicas, visto que é necessário que cada ente possua ligação com um sistema ou plataforma para a realização da licitação por meio do pregão eletrônico; assim, é imprescindível que a entidade tenha como requisito mínimo: pessoas preparadas e devidamente capacitadas a utilizarem a plataforma. Outro ponto que se coloca no processo como dificuldade é a eficácia do provedor de internet que se encontra instalado na entidade pública. $O$ acesso à internet é, ainda, um item que pode gerar problemas para os órgãos que pretendem utilizar a ferramenta, pois as dificuldades representadas quanto ao acesso é uma realidade em pequenos municípios, até mesmo com pequenos eletrônicos, tais como: smartphones, laptops e outros aparelhos tecnológicos. 
As adequações ao processo é uma necessidade, mas a prática dessa modalidade de licitação é uma vertente que ganha polpa com o uso adotado pelas entidades públicas em cidades com avanços tecnológicos mais expressivos, pois a fase de teste é um mecanismo que amplia as possibilidades deste modelo de licitação adentrar pelas regiões mais remotas e ser um ponto ainda mais eficaz junto àqueles que possuem menos recursos financeiros disponíveis.

Comparar os pontos positivos e negativos do pregão eletrônico em consonância com os pontos de eficiência da modalidade licitatória é um estudo que não finda as propostas de novas intervenções por parte de outros estudiosos acadêmicos. Esta pesquisa evidenciou uma lacuna de trabalhos que abordem a adoção e prática do pregão eletrônico em municípios de pequeno porte, fato que abre novos caminhos para pesquisas neste sentido. Propõe-se que as pesquisas tragam estudos de caso de sucesso ou fracasso na implementação do pregão eletrônico, de maneira que se possa aprofundar na questão prática da adoção desta modalidade.

A prática de uma pesquisa qualitativa junto aos pregoeiros para levantar as demandas locais é uma possibilidade a ser concretizada em novos estudos. $O$ artigo apresentado não trilhou esse caminho em razão dos efeitos nocivos da pandemia do Covid-19, pois os funcionários não se disponibilizaram a responder as perguntas, por hora motivados a manter 0 isolamento social, ação que se tornaria mais enriquecedoras com os relatos daqueles que se colocam na ponta do processo.

\section{Referências}

ALBIERO, Helton Jaques; SILVA, Marcelo Rodrigues da. Economicidade, eficiência e transparência nas compras públicas via pregão eletrônico: estudo de caso dos pregões eletrônicos 42/2012 e 32/2013 realizados pelo IFPR - Campus Assis Chateaubriand. ForScience: Revista Científica do IFMG, Formiga, v.6, n. 1, e 00275, jan. /jun. 2018

BATISTA, A. R. R. O pregão como ferramenta logística no processo de aquisição da administração Pública Brasileira. Brazilian Journal of Development, Curitiba, v. 5, n. 1, p. 1736-1745, Jan. 2019. Disponível em: http://www.brjd.com.br/. Acesso em: 10 abr. 2021.

BRASIL. Constituição da República Federativa do Brasil, de 5 de outubro de 1988. Disponível em: http://www.planalto.gov.br/. Acesso em: 18 abril 2021.

BRASIL. Lei Geral de Licitações - Lei no 8.666. Publicado em: 21 de jun. 1993. Disponível em: <http://www.planalto.gov.br/. Acesso em: 18 de abr. 2021.

BRASIL. Lei n.o 10.520. Publicado em: 17 de jul. 2002. Disponível em: http://www.planalto.gov.br/. Acesso em: 18 abril 2021.

BRASIL. Lei n.o 14.133. Publicado em: 01 de abr. 2021. Disponível em: http://www.planalto.gov.br/. Acesso em: 19 abril 2021.

BRASIL. Orientações para integração dos sistemas externos de compras eletrônicas com a Plataforma +Brasil. Ministério da Economia. Publicado: 28 de fev. 2020. Disponível em: http://plataformamaisbrasil.gov.br/. Acesso em: 27 de abr. 2021.

BRASILEIRO, Ada Magaly Matias. Como produzir textos acadêmicos e científicos. São Paulo: Editora Contexto, 2021.

BRASILEIRO, Ada Magaly Matias. Manual de produção de textos acadêmicos e científicos. São Paulo: Atlas, 2013. 
CARVALHO FILHO, José dos Santos. Manual de direito administrativo. $32^{\underline{a}}$ ed. Revisada. São Paulo: Atlas, 2018.

CAVALCANTE, S. O. R; SILVA, L. I. P. da; CENTENARO, M.; ZAMBERLAN, C. O. Análise do pregão eletrônico e presencial na universidade estadual do Mato Grosso do Sul. Revista Práticas de Administração Pública - RAP, v. 1, n. s, p. 119-138, 2017

COOPER, D. R.; SCHINDLER, P. S. Métodos de Pesquisa em Administração. 10ª ed. Porto Alegre: Bookman, 2011.

FARIA, E. R. et al. Fatores determinantes na variação dos preços dos produtos contratados por pregão eletrônico. Revista de Administração Pública, Rio de Janeiro, v. 44, n. 6, p. 1405-1428, nov. /dez. 2010.

FERNANDES, André Lezan. Compras na administração pública: o pregão eletrônico como instrumento de eficiência frente as modalidades da Lei n.. 8666/93. TCC do Curso de Bacharelado em Administração. Universidade Tecnológica Federal do Paraná, 2015.

FREITAS, Marcelo de; MALDONADO, José Manuel Santos de Varge. (2013). O pregão eletrônico e as contratações de serviços contínuos. Revista de Administração Pública, v. 47, n.․ 5, 2013, p. 1265-1281. Disponível em: https://doi.org/10.1590/S0034-76122013000500009. Acesso em 25 de abr. 2021.

GIL, Antônio Carlos. Métodos e técnicas de pesquisa social. 6ª ed. São Paulo: Atlas, 2008.

HEIDRICH, Krissia Karina; MENGDEN, Paulo Roberto de Aguiar Von. A participação do profissional contábil nos processos licitatórios municipais - estudo de caso no Vale do Paranhana. Revista Eletrônica Ciências Contábeis, 2014, p. 27 - 54. Disponível em: http://seer.faccat.br/. Acesso em 19 de abr. 2021.

MATIAS-PEREIRA, J. Manual de metodologia da pesquisa científica. $3^{\text {a }}$ ed. São Paulo: Atlas, 2012.

MINAYO, M. C. (Org.). Pesquisa social: teoria, método e criatividade. Petrópolis: Vozes, 2001.

NOHARA, Irene Patrícia. Direito administrativo. $7^{\mathfrak{a}}$ ed. Revisada. São Paulo: Atlas, 2017.

OLIVETTI, Rodrigo. O Impacto da Inversão de Fases e do Pregão Eletrônico na duração das Licitações Públicas. Trabalho de Conclusão de Curso de Especialização em Gestão Pública. Universidade Tecnológica Federal do Paraná. Pato Branco, 2014. Disponível em: http://repositorio.roca.utfpr.edu.br/. Acesso em 26 de abr. 2021.

SABATKE, Letícia Maiara. Aspectos positivos e negativos da aplicação do pregão eletrônico na administração pública e as inovações trazidas pelo Decreto no 10.024/19. Trabalho de Conclusão de Curso de Especialização em Gestão Pública Municipal - Universidade Tecnológica Federal do Paraná, Curitiba, 2020.

SILVA, Marcelo de Sousa. Implantação de um governo eletrônico: e-Gov. Rio de Janeiro: Brasport, 2012.

SPRICIGO, Paulo Roberto; FONSECA, Sergio Azevedo. Inovações nos procedimentos para compras e contratações na administração pública: breve avaliação das contribuições do pregão. Revista Temas de Administração Pública, v. 2, n. 3, 2008. Disponível em: https://www.fclar.unesp.br/. Acesso em: 20 de abr. 2021. 